\title{
DENTAL HYGIENISTS TARGET LIVERPOOL
}

This year's British Society for Dental Hygiene and Therapy's

(BSDHT's) Annual Oral Health Conference \& Exhibition

will take place at the Arena and Convention Centre (ACC) in

Liverpool on 9-10 November.

The ACC is located on Liverpool's stunning waterfront and is close to the Albert Dock and Tate Gallery.

The conference will include an impressive array of speakers, with presentations, workshops and a range of parallel sessions, all relevant to dental hygienists and dental hygienist/therapists, as well as other members of the team.

To register for the event go to www.bsdht.org.uk.

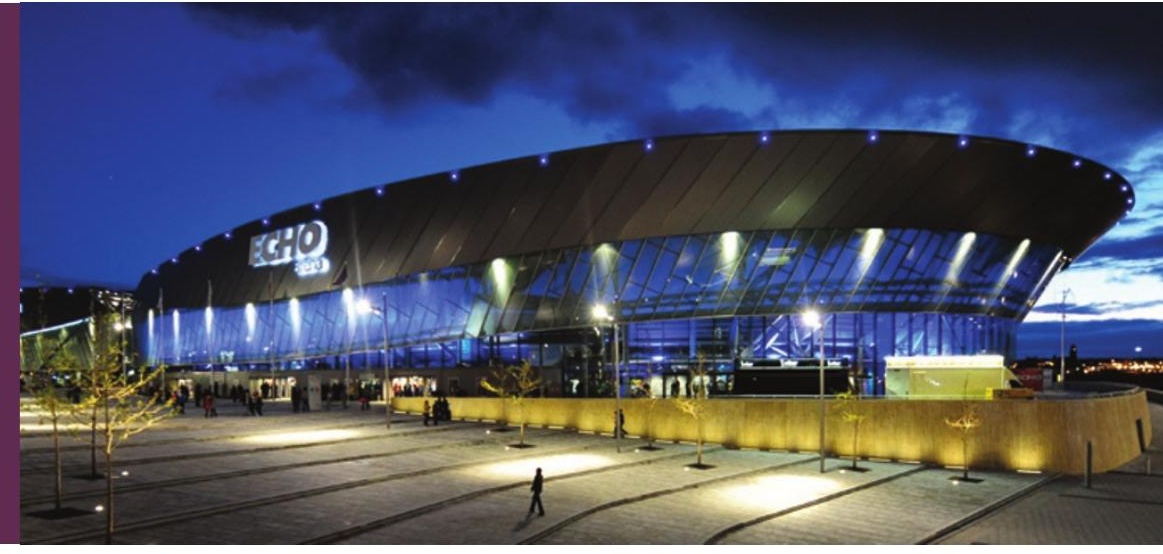

\section{PLANNING FOR LONDON 2013}

After three years in the North West of England, the 2013 - British Dental Conference and Exhibition will be held at ExCel London, on 25-27 April.

Building on this year's event in Manchester, where there were a record number of attendees, in 2013 there will be a number of enhanced features to ensure your time is inspirational, educational and enjoyable.

The event offers an excellent way to keep up to speed with developments in your profession; sample new I products; network with your peers; share knowledge and experience; and meet new career challenges.

Don't miss out: put the British Dental Conference and I Exhibition 2013 in your diary now! @BDAConference

\section{ANGELIC DEVILS RUN FOR CHARITY}

Eleven 'dental ladies' known as the 'Running Dental Devils' gathered in Finsbury Park, London on 7 July this year and raised over $£ 600$ for Cancer Research UK.

Laura Horton, Sylvie Sturrock and a number of other ladies working in the dental industry ran in a Race for Life event in 2010, but this year they chose a location that offered $5 \mathrm{~km}$ and $10 \mathrm{~km}$ distances. Five of this year's group ran 10 $\mathrm{km}$ and six ran $5 \mathrm{~km}$.

'We had a fantastic day even though there was a major downpour before the race, said Laura Horton. 'The sense of achievement and the mood among the team when we finished was fabulous. Achieving something as part of a group is much more rewarding than doing so alone.

The Running Dental Devils were very grateful to Wil Watts, Events Manager at dental CPD training centre Seminars@thirtyeight, who waited in the mud and rain to look after the ladies' bags!

To see more photographs from the day and to stay informed about the 2013 event, visit www.facebook.com/therunningdentaldevils.

\section{DENTAL NURSES TO ZUMBA}

\section{ON THE GOLDEN MILE}

This year's National Dental Nursing

Conference will be held at the

Blackpool Hilton on 24 November

2012. A new one day format is being trialled in response to a survey conducted by the British Association of Dental Nurses (BADN).

'Holding a one day conference allows us to keep the cost down:' said BADN President Nicola Doherty. 'This year, with generous sponsorship from the BDTA, the conference registration fee is less than $£ 50$ for BADN members, and offers four and a half hours of verifiable CPD.' A nonmember price is also available.

The fee includes lunch, refreshments and pre-lunch Zumba.

On the evening before the conference, delegates are invited to join Nicola and other BADN Council members at an informal dinner at Harry Ramsden's fish and chip restaurant just below Blackpool Tower. www.badn.org.uk/ conference

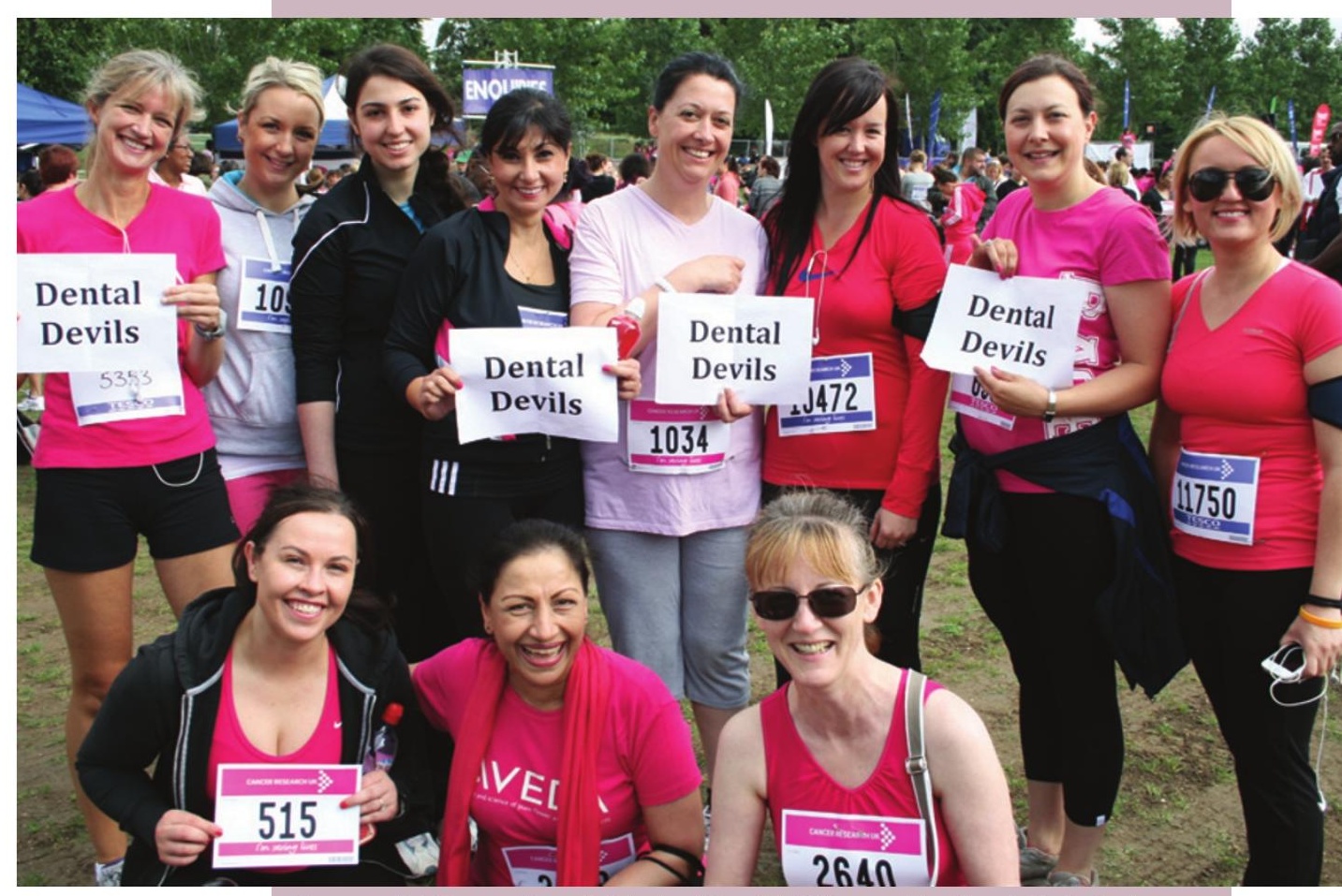

Top row (I-r) Gaynor Barrett, Principal Dentist, 38 Devonshire Street; Shelly Foster, Clinical Manager, Abi Dental; Noor Sharif, 2nd Year dental student, Barts; Abi Al-adhami, Principal Dentist, Abi Dental; Sylvie Sturrock, Business Manager, The Neem Tree Dental Group; Laura Horton, Director \& Trainer, Laura Horton Consulting; Felicity Cleaver, Practice Development Manager, Love Your Smile Surbiton; Cristina Sabau, Business Development Manager, Chiral Systems Ltd. Front row (I-r) Janine Grayling, Dental Recruitment Consultant, The Dental Recruit Network; Ruby Bhachu, Mary Lupton, both dental nurses at 38 Devonshire Street 